\title{
From Threat to Fear: The Neural Organization of Defensive Fear Systems in Humans
}

\author{
Dean Mobbs, ${ }^{1,2}$ Jennifer L. Marchant, ${ }^{1}$ Demis Hassabis, ${ }^{1}$ Ben Seymour, ${ }^{1}$ Geoffrey Tan, ${ }^{1}$ Marcus Gray, ${ }^{1,5}$ \\ Predrag Petrovic, ${ }^{1,3}$ Raymond J. Dolan, ${ }^{1}$ and Christopher D. Frith ${ }^{1,4}$ \\ ${ }^{1}$ Wellcome Trust Centre for Neuroimaging, University College London, London WC1 3BG, United Kingdom, ${ }^{2}$ Medical Research Council-Cognition and \\ Brain Sciences Unit, Cambridge CB2 7EF, United Kingdom, ${ }^{3}$ Department of Clinical Neuroscience, Karolinska Institute, 7176 Stockholm, Sweden, ${ }^{4}$ Centre \\ for Functional Integrative Neuroscience, Aarhus University Hospital, DK-800 Aarhus C, Denmark, and ${ }^{5}$ Clinical Imaging Sciences Centre, Brighton and \\ Sussex Medical School, University of Sussex, Brighton, East Sussex BN1 9PX, United Kingdom
}

Postencounter and circa-strike defensive contexts represent two adaptive responses to potential and imminent danger. In the context of a predator, the postencounter reflects the initial detection of the potential threat, whereas the circa-strike is associated with direct predatory attack. We used functional magnetic resonance imaging to investigate the neural organization of anticipation and avoidance of artificial predators with high or low probability of capturing the subject across analogous postencounter and circa-strike contexts of threat. Consistent with defense systems models, postencounter threat elicited activity in forebrain areas, including subgenual anterior cingulate cortex (sgACC), hippocampus, and amygdala. Conversely, active avoidance during circa-strike threat increased activity in mid-dorsal ACC and midbrain areas. During the circa-strike condition, subjects showed increased coupling between the midbrain and mid-dorsal ACC and decreased coupling with the sgACC, amygdala, and hippocampus. Greater activity was observed in the right pregenual ACC for high compared with low probability of capture during circa-strike threat. This region showed decreased coupling with the amygdala, insula, and ventromedial prefrontal cortex. Finally, we found that locomotor errors correlated with subjective reports of panic for the high compared with low probability of capture during the circa-strike threat, and these panic-related locomotor errors were correlated with midbrain activity. These findings support models suggesting that higher forebrain areas are involved in early-threat responses, including the assignment and control of fear, whereas imminent danger results in fast, likely "hard-wired," defensive reactions mediated by the midbrain.

\section{Introduction}

Evolution has endowed all living organisms with a repertoire of adaptive responses to circumvent a wide range of ecological dangers (Bolles and Fanselow, 1980). One influential model posits that distinct types of threat are compartmentalized into several core contexts along a "threat imminence continuum" (Fanselow and Lester, 1988; Bouton et al., 2001). In the context of a predator, the postencounter reflects the initial detection of the potential threat, whereas the circa-strike is associated with direct interaction with the predator (i.e., when the predator attacks). The postencounter is linked with "passive freezing" and elevated anticipatory anxiety when an aversive stimulus is remote in time (Bouton et al., 2001). The "circa-strike" is exemplified by fear, "active escape and avoidance," and panic surges associated with imminent threat (Craske, 1999; Gray and McNaughton, 2000; Bouton et al., 2001; Phelps and LeDoux, 2005; Rau and Fanselow, 2007). Although these biologically potent defense reactions to postencounter and circa-strike threat are well-characterized in

\footnotetext{
Received May 21, 2009; accepted July 1, 2009.

This work was funded by the Wellcome Trust research programme grants. D.M. was supported by a Brain Research Trust Prize studentship and the Medical Research Council. We thankC. Hagan, L. Passamonti, CHutton, and N. Weiskopf for discussions and help with data analysis.

Correspondence should be addressed to Dr. Dean Mobbs, Medical Research Council-Cognition and Brain Sciences Unit, 15 Chaucer Road, Cambridge CB2 7EF, UK. E-mail: dean.mobbs@mrc-cbu.cam.ac.uk. DOI:10.1523/JNEUROSCI.2378-09.2009

Copyright $\odot 2009$ Society for Neuroscience $\quad$ 0270-6474/09/2912236-08\$15.00/0
}

rodents, no studies have explicitly explored these fear contexts in humans.

It has been theorized that the inhibitory interactions between the brain systems supporting the postencounter and circa-strike threat allow the organism to rapidly switch between evolutionary conserved defense reactions (Fanselow and Lester, 1988). Postencounter and circa-strike defensive states are thought to be topographically organized along a medial prefrontal cortical (mPFC) network (Blanchard et al., 1990a; Fanselow, 1994; Price, 2005), an hierarchical continuum supported by brain defense system models (Deakin and Graeff, 1991; McNaughton and Corr, 2004; Burghardt et al., 2007; Lowry et al., 2008). In essence, these models posit that when a remote threat is confronted, specialized higher corticolimbic regions including the ventral mPFC (vmPFC) and hippocampus gather contingency and contextual information and, via the amygdala instigate survival actions by controlling midbrain systems [e.g., ventrolateral periaqueductal gray (PAG) evoked freezing] (Fanselow, 1994; LeDoux, 1996; Amat et al., 2005, 2006; Quirk and Beer, 2006; Schiller et al., 2008; Jhou et al., 2009). Conversely, imminent threat in the form of circa-strike corresponds with the inhibition of forebrain circuits, with midbrain regions such as the dorsolateral PAG becoming dominant, which, in turn, engineer active defense reactions [e.g., fight or flight (Fanselow and Lester 1988; Blanchard and Blanchard, 1990b; Bandler et al. 2000; Dayan and Huys, 2009; Robbins and Crockett, 2009)]. 
In the current study, we build on previous observations (Mobbs et al., 2007) that have showed simple proximity effects during active avoidance of a predator, in which brain activity switches from prefrontal cortical areas to midbrain areas as a predator comes closer. Here, we explicitly examine distinct contextual fear states along a threat continuum (i.e., postencounter vs circa-strike context; see Fig. $1 A-I)$. Furthermore, we also manipulate probability of capture (i.e., shock), which has previous been hypothesized to relate to distance along the threat imminence continuum (Bolles and Fanselow, 1980; Fanselow and Lester, 1988). Therefore, to gain a clearer picture of these ecologically defined contexts, we combined capture probability with early danger (i.e., postencounter) versus imminent danger (i.e., circa-strike) detection.

Consistent with previous findings (Mobbs et al., 2007), we predict that the midbrain is associated with immediate circa-strike, whereas postencounter threat recruits the vmPFC, hippocampus, and amygdala regions implicated in coding fear contingency, context, vigilance, and behavioral control (LeDoux, 1996; Davis and Whalen, 2001; Amat et al., 2005; Schiller et al., 2008). We also aimed to assess a simple putative analog of panic: we reasoned that a high probability of capture during the circa-strike would result in increased locomotor errors, psychophysiological arousal (i.e., skin conductance), and recruitment of midbrain structures implicated in panic. Last, to further characterize these fear states, we examined functional coupling between these regions to characterize the hypothesized inhibitory relationship between midbrain and forebrain areas as determined by threat context.

\section{Materials and Methods}

\section{Subjects}

Twenty-four healthy subjects ( 12 males; mean age and SD $27.0 \pm 4.7$ ) were scanned. All were right-handed, had normal or corrected vision, and were screened for a history of psychiatric or neurological problems. All subjects gave informed consent, and the study was approved by the joint Ethics Committee of the National Hospital for Neurology and Neurosurgery (University College London Hospital National Health Service Trust) and the Institute of Neurology.

\section{Pain calibration}

A cutaneous electrical pain stimulation was applied to the dorsum of the left hand for 1 or $3 \mathrm{~ms}$ via an in-house built functional magnetic resonance imaging (fMRI) compatible electrical stimulator. Each subject was allowed to calibrate the shocks to their own tolerance level. The intensity of the shock was tested before the experiment and set to the maximum tolerable painful stimulation $(<20 \mathrm{~mA})$. The average shock intensity was $10.3 \pm 2.6 \mathrm{~mA}$.

\section{Artificial intelligence predator model}

The computerized predator was programmed using a standard algorithm in artificial intelligence. More specifically, we implemented a recursive breadth-first flood-fill search algorithm (Russell and Norvig, 2003) to control the behavior of the artificially intelligent predator. This works by computing the distance to the target prey for each of the valid adjacent positions (i.e., not wall blocks) to the current predator position and selecting the one with the shortest distance as the predator's next movement. Distances are computed by a recursive search algorithm that maintains a queue of current search positions. On each pass of the algorithm, each position in the queue is removed, and in its place, all the valid adjacent positions (excluding its "parent" position in the search tree) are added. When one of the search paths reaches the target prey position, all other searches are terminated, and the path and its distance are returned (i.e., a breadth-first search). For mazes with no dead ends, as used in this study, this algorithm yields the optimal strategy for the high probability of capturing the subject $\left(\mathrm{CS}_{\mathrm{HI}}\right)$ or $\mathrm{CS}_{\mathrm{LO}}$. For both $\mathrm{CS}_{\mathrm{HI}}$ and $\mathrm{CS}_{\mathrm{LO}}$, the speed linearly increased after $15 \mathrm{~s}$ in the maze until the subject was caught by the $\mathrm{CS}_{\mathrm{HI}}\left(87.5 \%\right.$ of the time) and $12.5 \%$ of the $\mathrm{CS}_{\mathrm{LO}}$ trials. Probability of capture in the circa-strike conditions was achieved by making the artificial predator disappear when within one-to-three squares away from the subjects' blue triangle.

\section{Paradigm}

Subjects were presented with a two-dimensional maze containing a $9 \times$ 13 rectangle grid of walls $(\square)$ and paths ( $\square$; see Fig. 1). The paradigm consisted of three core contexts. All experimental contexts commenced with a pre-encounter context $(\mathrm{PrE})$ in which a maze appeared surrounded by a gray box. During this context, the subject was asked to navigate a triangle toward flashing yellow squares presented for $100 \mathrm{~ms}$ and appearing at different locations every $5 \mathrm{~s}$. Next, subjects either moved to the "postencounter" context, which was separated into two contexts, each determined by the color of the box surrounding the maze. An orange box (postencounter high probability of capture; $\mathrm{PE}_{\mathrm{HI}}$ ) indicated to the subject that there was a probability $(16$ blocks $=69.6 \%)$ of moving on to the circa-strike contexts with the circa-strike predator with $\mathrm{CS}_{\mathrm{HI}}$. Likewise, a purple box $\left(\mathrm{PE}_{\mathrm{LO}}\right)$ signaled that there was a probability (16 blocks $=69.6 \%$ probability) that the subject would move on to encounter the circa-strike predator with $\mathrm{CS}_{\mathrm{LO}}$. A green box (safe context; SC) indicated to the subjects that they would avoid any interaction with the artificial predator (14 blocks). The final context was the circa-strike in which the artificial predator began to chase and attempt to capture the subject. The subject's goal was to try and avoid the artificial predator for as long as possible. The orange $\mathrm{CS}_{\mathrm{HI}}$ predator caught the subject on $87.5 \%$ of the trials. Conversely, the purple $\mathrm{CS}_{\mathrm{LO}}$ predator was nonoptimal with $\mathrm{CS}_{\mathrm{LO}}$ (i.e., capture on $12.5 \%$ of the trials). The difficulty of each game was set on a person-by-person basis, using performance in the training session. Capture was manipulated by making the artificial predator disappear from three to one squares from the subject's blue triangle. When the subjects were caught, a $2 \mathrm{~s}$ wait was given before one shock ( $50 \%$ of the time) or three shocks ( $50 \%$ of the time) were administered. A $2 \mathrm{~s}$ rest was given before the subject moved back to the next "preencounter" context. The exact instructions can be found in supplemental materials (available at www.jneurosci.org).

\section{Questionnaires}

After scanning, subjects completed a questionnaire that asked them to indicate on a 10-point analog scale (1) how much anxiety they felt in the preferred, pre-encounter, postencounter, and circa-strike contexts and (2) how much panic they felt in the postencounter and circa-strike contexts. An example of a question is, "Did you panic when the orange circle got close to you in the chase condition?" See supplemental material (available at www.jneurosci.org) for more examples.

\section{fMRI acquisition}

A 3T Allegra head scanner (Siemens Medical Systems) with standard transmit-receive head coil was used to acquire functional data using echoplanar imaging (EPI) sequences (matrix size, $64 \times 64$; Fov, $192 \times$ $192 \mathrm{~mm}$; in-plane resolution, $2 \times 2 \mathrm{~mm}$; 40 slices with interleaved acquisition; slice thickness, $2 \mathrm{~mm}$ with a $1 \mathrm{~mm}$ gap between slices; repetition time, $2.6 \mathrm{~ms}$ ). To maximize statistical power, we used only 40 slices that were optimized to cover the brainstem and angled at $-30^{\circ}$ to cover the whole brain. The slice tilt, $\mathrm{z}$-shim gradient compensation reduced signal loss in the vmPFC (Weiskopf et al., 2006). In addition, field maps were acquired for reduction of geometric distortions of the EPI images (Hutton et al., 2002). A high-resolution T1-weighted structural scan was obtained for each subject $[1 \mathrm{~mm}$ isotropic resolution three-dimensional modified driven equilibrium Fourier transform (Deichmann et al. 2004)] and coregistered to the subject's mean EPI. The average of all structural images permitted the anatomical localization of the functional activations at the group level.

\section{fMRI analysis}

Statistical parametric mapping (SPM5; Wellcome Trust Centre for Neuroimaging, www.fil.ion.ucl.ac.uk) was used to preprocess all fMRI data and included spatial realignment, coregistration, normalization, and smoothing. To control for motion, all functional volumes were realigned to the mean volume. Using the FieldMap toolbox, field maps were estimated from the phase difference between the images acquired at the short and long echo time and unwrapped (Hutton et al., 2002). Voxel displace- 
ments in the EPI were determined from the field map and EPI parameters. Distortions were corrected by applying the inverse displacement to the EPIs. Images were spatially normalized (Ashburner and Friston, 1999) to standard space Montreal Neurological Institute template with a voxel size of $2 \times 2 \times 2 \mathrm{~mm}$ and smoothed using a Gaussian kernel with an isotropic full width at half maximum of $8 \mathrm{~mm}$. In addition, high-pass temporal filtering with a cutoff of $128 \mathrm{~s}$ was applied to remove lowfrequency drifts in signal, and global changes were removed by proportional scaling.

After preprocessing, statistical analysis was conducted using the general linear model. Analysis was performed to determine each subject's voxelwise activation during artificial predator and yoked contexts. Activated voxels in each experimental context were identified using a statistical model containing boxcar waveforms representing each of the four experimental contexts, convolved with a canonical hemodynamic response function, and mean-corrected (Turner et al., 1991). The cardiac noise correction was implemented at the level of modeling the measured signal and not at the level of image reconstruction, i.e., image data were not modified. The underlying model assumed that cardiac effects on a voxel's signal depend on the phase of the image slice acquisition within the cardiac cycle. Sine and cosine series ( $\leq$ third order) were used to describe the phase effect on a single reference slice (passing through PAG), creating six regressors (Josephs et al., 1997).

\section{Connectivity analyses}

Psychophysiological interaction. In our study, the connectivity arising from different fear context is modulated by the following contrast: $\left[\left(\mathrm{CS}_{\mathrm{HI}}-\mathrm{PE}_{\mathrm{HI}}\right)-\left(\mathrm{CS}_{\mathrm{LO}}-\mathrm{PE}_{\mathrm{LO}}\right)\right]$. We sought to identify "target areas," which had differential connectivity with the source region in the midbrain. This was achieved using a moderator variable, derived from the product of source activation and context. Hence, for the subsequent functional connectivity analyses, the midbrain was chosen as the source region. For each participant, we computed the above contrasts to determine the local maximum that was the nearest voxel to the activation peak in the midbrain defined by the whole-group cluster (supplemental Tables 1 and 3, available at www.jneurosci.org as supplemental material). Analysis used a standardized $6 \mathrm{~mm}$ sphere across all participants for midbrain: seed location: $x=8, y=-26$, and $z=-8$, which was the maximal voxel. Using these same procedures, we also examined the connectivity for the $\mathrm{CS}_{\mathrm{HI}}-\mathrm{CS}_{\mathrm{LO}}$ contrast using a right pregenual anterior cingulate cortex (pgACC) seed $(x=20, y=44$, and $z=6)$.

Skin conductance response analysis. In parallel to the acquisition of the fMRI data, we continuously monitored skin conductance level (SCL), from electrodes placed on the middle and index fingers of the left hand. However, as a result of technical problems, one subject was dismissed from the analysis. Thus, we recorded skin conductance data in 23 subjects out of 24 . Skin conductance data were segmented into single epochs containing pre-encounter, postencounter, and circa-strike phases, and where necessary, individual epochs were rotated to correct for drift. Mean SCLs were then calculated for each phase within an epoch, and each subject normalized by setting the maximum and minimum of all means to 100 and 0 , respectively. Finally, to allow for meaningful comparison, we adjusted the $\mathrm{CS}_{\mathrm{HI}}$ and $\mathrm{CS}_{\mathrm{LO}}$ conditions so that group means (PrEs) began at 0 .

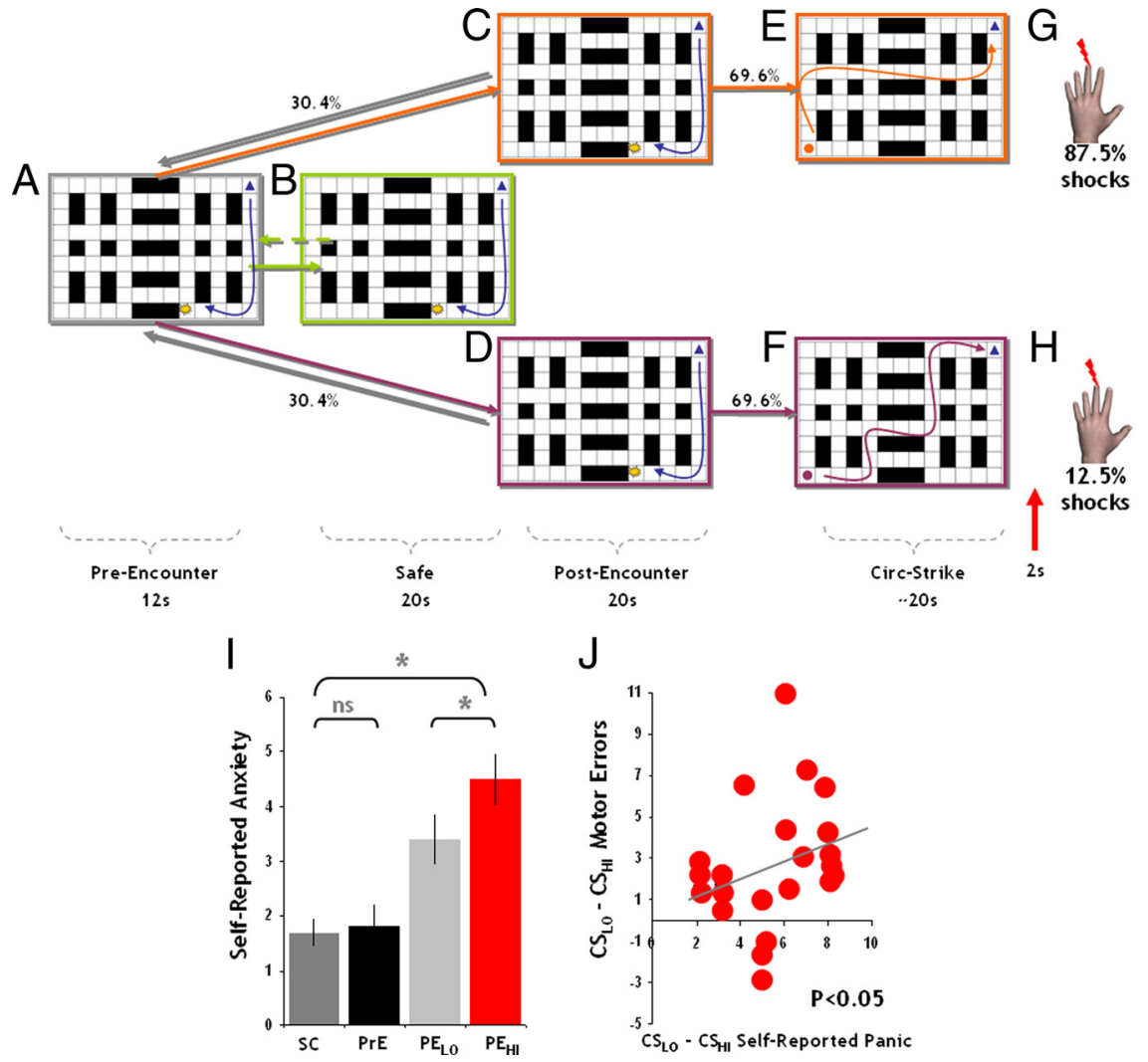

Figure 1. Schematic representation of the paradigm and subjective scores for task relating to anxiety, panic, and panic-related triangle. The $\mathrm{CS}_{H}$ predator captured subjects on $87.5 \%$ of the trials $(\boldsymbol{G})$, and the $C S_{L O}$ predator captured the subjects on $12.5 \%$ of the f the right hand with $50 \%$ probability. Subjective scores for $(I)$ self-reported anxiety for all fear states. $J$, The correlation between

\section{Results}

Subjective ratings of panic and anxiety

We first examined subjective reports of anxiety and fear using postexperimental questionnaires. Both $\mathrm{PE}_{\mathrm{HI}}$ and $\mathrm{PE}_{\mathrm{LO}}$ predator interactions were rated as causing significantly more anxiety than the safe (mean $\pm \mathrm{SD}, 1.8 \pm 1.2)$ and pre-encounter $(1.8 \pm 1.9)$ contexts (Wilcoxon signed ranks test, $p<0.001$, one-tailed) (Fig. $1 I$ ). Greater anxiety was observed when encountering the $\mathrm{CS}_{\mathrm{HI}}$ predator $\left(\mathrm{CS}_{\mathrm{HI}}, 4.5 \pm 2.2 ; \mathrm{CS}_{\mathrm{LO}}, 3.5 \pm 2.1 ; Z=-2.844 ; p=\right.$ $0.004)$. No significant differences were found between safe (SC) and the $\operatorname{PrE}(Z=-0.333 ; p=0.739)$. For subjective ratings of panic, a significant difference was evident between the $\mathrm{CS}_{\mathrm{HI}}$ $(5.5 \pm 2.2)$ and $\mathrm{CS}_{\mathrm{LO}}$ predator $(4.7 \pm 1.8 ; Z=-2.473 ; p=$ $0.013)$. Panic was also rated as being significantly higher for the $\mathrm{CS}_{\mathrm{HI}}$ conditions compared with the $\mathrm{PE}_{\mathrm{HI}}$ conditions $(2.9 \pm 1.9$; $Z=-3.8 ; p=0.0005)$. A similar pattern was observed for the $\mathrm{CS}_{\mathrm{LO}}$ conditions compared with the $\mathrm{PE}_{\mathrm{LO}}$ conditions $(2.3 \pm 1.58$; $Z=-4.1 ; p=0.0005)$.

\section{Panic-related locomotor errors}

We also used an indirect measure of panic. Specifically, we tested if locomotor errors quantified by calculating the amount of button presses directed into the walls of the maze, during the circa-strike, were indicative of disorganized behavior typically 
A

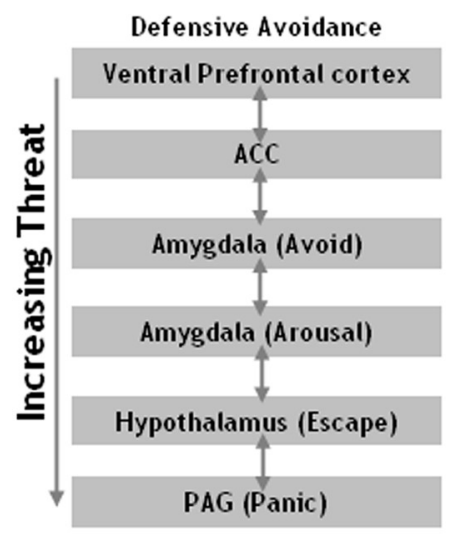

B

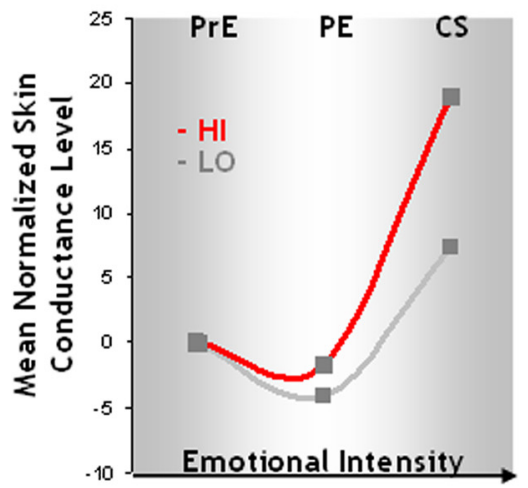

C

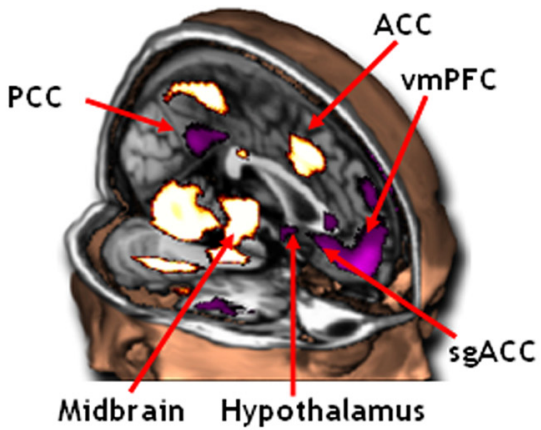

G

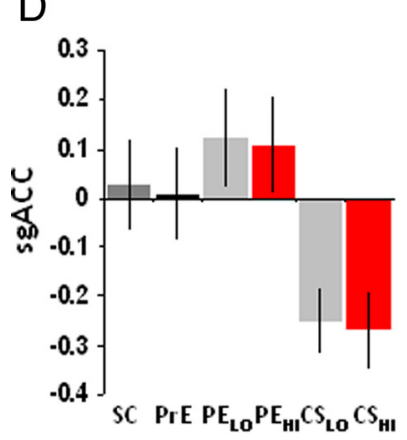

$\mathrm{E}$

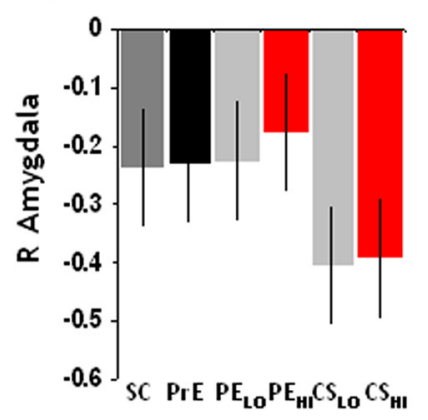

$\mathrm{F}$

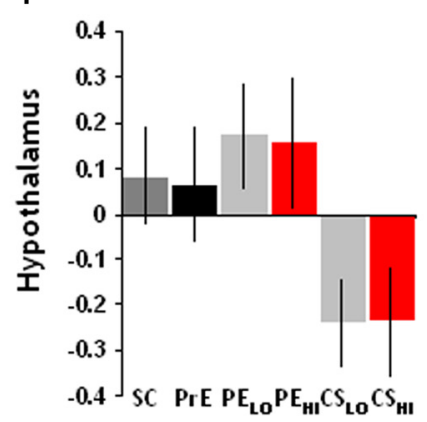

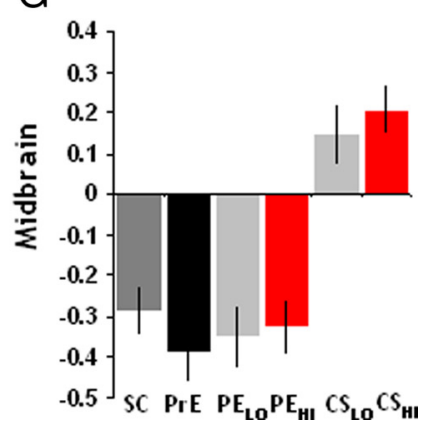

Figure 2. Theoretical model of defense avoidance, SCLS, and fMRI results. $\boldsymbol{A}$, McNaughton and Corr's defense avoidance model (McNaughton and Corr, 2004). $\boldsymbol{B}$, Mean-normalized SCLs for the pre-encounter and postencounter and circa-strike contexts. C, BOLD signal for the interaction between circa-strike (shown in orange) and postencounter contexts (shown in purple); parameter estimates for activity in the sgACC $(0,26,-12 ; p<0.005 \mathrm{svc})(\boldsymbol{D})$, right amygdala $(24,-8,-24 ; p<0.0005 \mathrm{svc})(\boldsymbol{E})$, hypothalamus $(-2,2,-12 ; p<0.002 \mathrm{svc})(\boldsymbol{F})$, and midbrain $(8,-26,-8$; $p<0.0005$ (G); family wise error corrected for whole brain (FWEcorr).

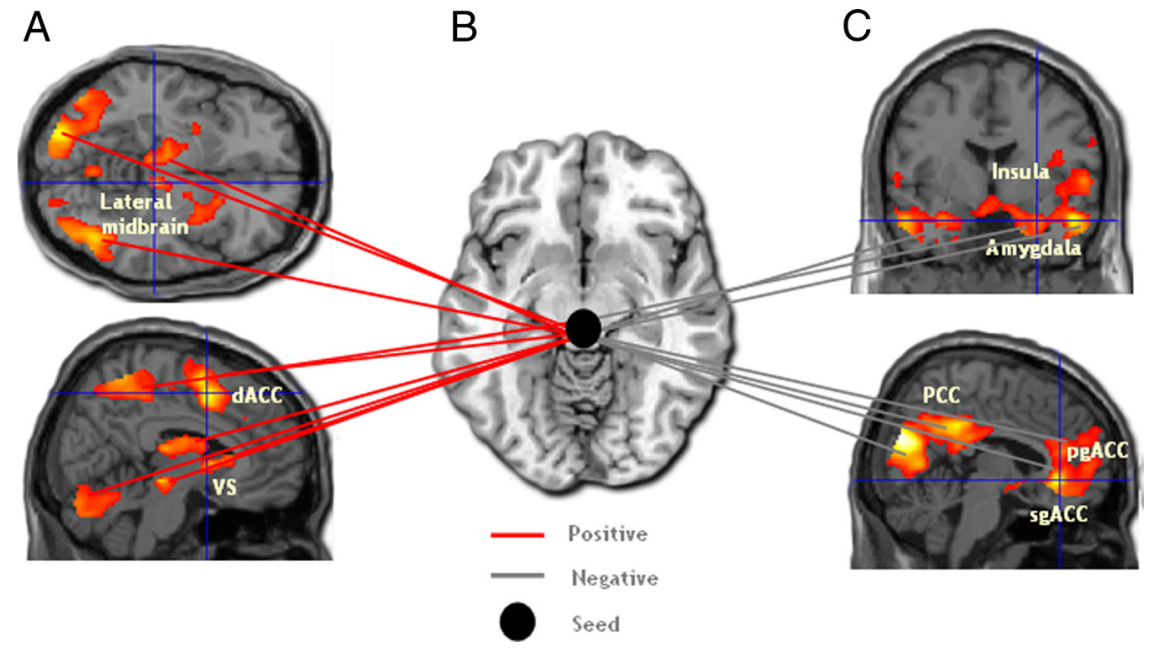

Figure 3. PPIs from the midbrain seed. $A$, Positive connectivity with the $\mathrm{dACC}$ and lateral midbrain. $\boldsymbol{B}$, Midbrain seed (seed location, $8,-26,-8)$. C, Negative PPIs with the sgACC, pgACC, PCC, insula, amygdala, ventral striatum (VS), and hippocampus. Blue arrow indicates negative connectivity. Red arrow indicates positive coupling.

observed during panic (Fanselow, 1988) and conditions where there is a high probability of capture (McNaughton, 1993). Because we expected more panic-like locomotor errors when subjects encountered the $\mathrm{CS}_{\mathrm{HI}}$ predator, we first tested if subjects made more errors for the $\mathrm{CS}_{\mathrm{HI}}$ compared with the $\mathrm{CS}_{\mathrm{LO}}$ (Wilcoxon signed ranks test, $Z=0.44 ; p=0.032)$. No significant differences were found for the $\mathrm{PE}_{\mathrm{HI}}$ and $\mathrm{PE}_{\mathrm{LO}}$ conditions $(Z=$ $-0.815 ; p=0.415)$. We next subtracted the number of errors for the $\mathrm{CS}_{\mathrm{LO}}$ from the $\mathrm{CS}_{\mathrm{HI}}$ predator and correlated the residual locomotor errors (divided by time to account for time differences between the $\mathrm{CS}_{\mathrm{HI}}$ and $\mathrm{CS}_{\mathrm{LO}}$ condition) with subjective ratings of panic. We found a positive correlation between amount of panic-like errors and self-reported panic for the $\mathrm{CS}_{\mathrm{HI}}$ condition (Spearman, $r=0.35 ; p=$ 0.048) (Fig. $1 J$ ).

\section{Skin conductance levels}

Concomitant recordings of SCLs were taken during the whole experiment. We ran a repeated-measures ANOVA on probability of capture and postencounter and circa-strike conditions. In addition to significant main effects for conditions $\left[F_{(22)}=66.275 ; p=0.0005\right]$ and capture probability $\left[F_{(22)}=28.868\right.$; $p=0.0005]$, we found an interaction $\left[F_{(22)}=32.129 ; p=0.0005\right]$, indicating that SCL increases from postencounter to circa-strike were considerably larger for the encounter with the $\mathrm{CS}_{\mathrm{HI}}$ predator (Fig. $2 \mathrm{~B}$ ).

\section{fMRI results}

Postencounter versus circa-strike contexts

For the fMRI analysis, we first examined the interaction highlighting postencounter contexts [i.e. $\left(\mathrm{PE}_{\mathrm{HI}}-\mathrm{CS}_{\mathrm{HI}}\right)-\left(\mathrm{PE}_{\mathrm{LO}}-\right.$ 


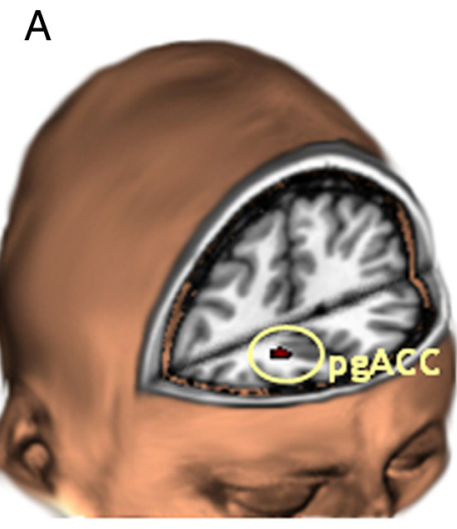

C
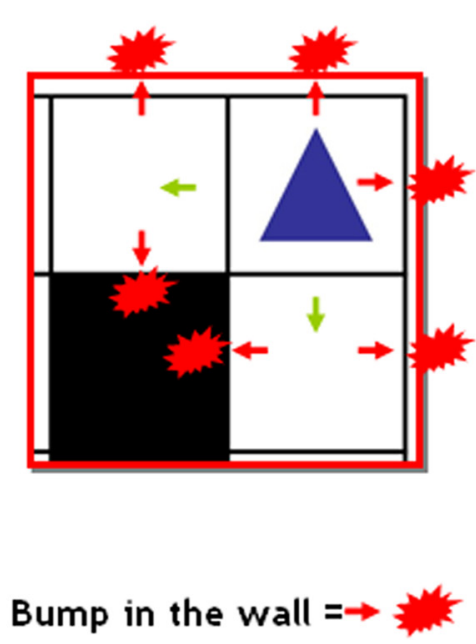

B

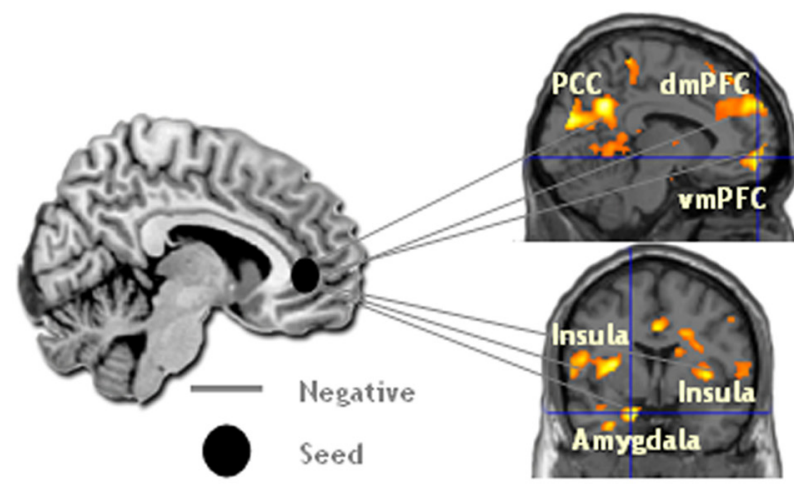

D

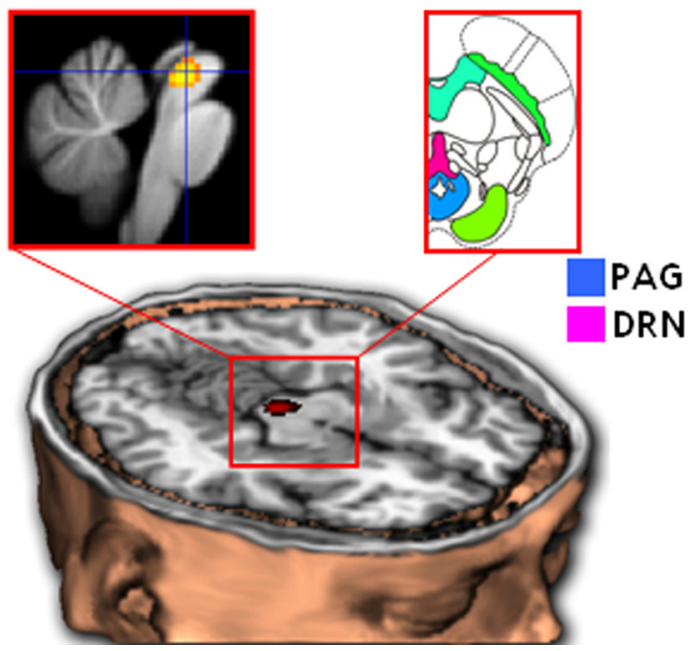

Figure 4. Direct comparison between $\mathrm{CS}_{\mathrm{HI}}-\mathrm{CS}_{\mathrm{LO}}$ conditions and panic-related locomotor errors. $A$, Render showing right pgACC activity $(20,44,6 ; p<0.024 \mathrm{svc})$ and parameter estimates for the $C_{I S}-C S_{E S}$ comparison. $\boldsymbol{B}$, PPI analysis showing decreased coupling, most notably the left amygdala $(-20,2,-24 ; p<0.05$ svc). The gray arrows denote negative coupling. $\boldsymbol{C}$, How panic-related motors errors were quantified. Red arrows equate to bumps in the wall (i.e., locomotor errors). Green arrows indicate smooth uninterrupted movements through the maze. $\boldsymbol{D}$, correlations between midbrain activity and panic-related locomotor errors $(0,-28,-8 ; p<0.05 \mathrm{svc})$.

$\left.\mathrm{CS}_{\mathrm{LO}}\right)$ ]. In this analysis, we observed increased posterior cingulate cortex (PCC), bilateral hippocampus, hypothalamus, amygdala, vmPFC, and subgenual ACC (sgACC) activity (Fig. $2 C-G$; supplemental Table S1, available at www.jneurosci.org as supplemental material).

Circa-strike versus postencounter contexts

For the interaction highlighting circa-strike context [i.e. $\left(\mathrm{CS}_{\mathrm{HI}}-\right.$ $\left.\left.\mathrm{PE}_{\mathrm{HI}}\right)-\left(\mathrm{CS}_{\mathrm{LO}}-\mathrm{PE}_{\mathrm{LO}}\right)\right]$ increased activity was observed in the midbrain, mediodorsal thalamus, right striatum, right insula, and dorsal ACC (dACC) (Fig. 2C-G, supplemental Table S1, available at www. jneurosci.org as supplemental material). To investigate activity in these regions further, we examined the psychophysiological interaction (PPI) (i.e., functional coupling) with the PAG for the contrast $\left[\left(\mathrm{CS}_{\mathrm{HI}}-\mathrm{PE}_{\mathrm{HI}}\right)-\left(\mathrm{CS}_{\mathrm{LO}}\right.\right.$ $\left.\left.-\mathrm{PE}_{\mathrm{LO}}\right)\right]$. A midbrain seed region revealed positive connectivity with the dACC, ventral striatum, medial dorsal thalamus, anterior insula, and lateral midbrain (Fig. $3 A$ ) and negative connectivity with the right amygdala, hippocampus, insula, vmPFC, PCC, and sgACC (Fig. 3B, supplemental Table S2, available at www.jneurosci.org as supplemental material).

$C S_{H I}$ versus $C S_{L O}$ conditions

To examine the neural systems associated with probability of capture, we next directly compared $\mathrm{CS}_{\mathrm{HI}}$ and $\mathrm{CS}_{\mathrm{LO}}$ conditions.
The main effect of $\mathrm{CS}_{\mathrm{HI}}>\mathrm{CS}_{\mathrm{LO}}$ revealed increased vmPFC activity, namely the pgACC. Another cluster was observed in the dorsal mPFC (Fig. 4A, supplemental Table S3, available at www.jneurosci.org as supplemental material). Using the right pgACC peak coordinate as a seed, we also conducted a PPI analysis showing this region to have decreased connectivity with the amygdala, insula, and vmPFC (Fig. 4 B, supplemental Table S4, available at www. jneurosci.org as supplemental material). To further interrogate this activity, we examined the covariation between State Anxiety Inventory trait anxiety scores and blood oxygenation level-dependent (BOLD) signal for the main effect of $\mathrm{CS}_{\mathrm{HI}}>\mathrm{CS}_{\mathrm{LO}}$ showing increased correlation with the bilateral amygdala and sgACC (supplemental Table S5, available at www.jneurosci.org as supplemental material). Supporting the putative role of the pgACC in high shock probability, we also observed activity in this region for the interaction between $\mathrm{CS}_{\mathrm{HI}}$ and $\mathrm{PE}_{\mathrm{HI}}$ conditions (pgACC, 20, 44, 6; $p<0.001$ ).

$C S_{H I}$ versus $C S_{L O}$ : panic-related locomotor errors

To probe the relationship between panic and shock probability more directly, we next subtracted the $\mathrm{CS}_{\mathrm{LO}}$ condition locomotor errors from the $\mathrm{CS}_{\mathrm{HI}}$ and correlated the residual errors with the BOLD signal for the $\mathrm{CS}_{\mathrm{HI}}-\mathrm{CS}_{\mathrm{LO}}$ comparison. This analysis showed the left PAG, dACC, and right insula activity correlated 
with panic-related locomotor errors (supplemental Fig. S6, available at www.jneurosci. org as supplemental material). Decreased panic-like errors elicited activity in the ventrolateral prefrontal cortex and pgACC, albeit somewhat weaker $(p<0.005)$.

\section{Discussion}

We set out to characterize the neural systems associated with ethologically defined postencounter and circa-strike threat contexts, as well as how these systems are influenced by capture probability. Our key neurobiological findings show that an early anticipation of a possible nociceptive event (i.e., the postencounter) increased activity in a set of forebrain structures, most prominently the vmPFC, hippocampus, hypothalamus, and amygdala. Imminent threat in the form of circa-strike elicited activity in midbrain regions, including the PAG and cortical regions, known to be involved in analgesia and panic (i.e., dACC) (Petrovic et al., 2002; Tamburin et al., 2008). Encountering the $\mathrm{CS}_{\mathrm{HI}}$ elicited pgACC activity consistent with the notion that this region is involved in behavioral control and analgesia (Petrovic et al., 2002; Amat et al., 2005; Schiller et al., 2008). Finally, we show for the first time a neurobehavioral index of panic in which elevated locomotor errors were associated with increased with midbrain activity. Our observations have strong resonance to theoretical models of threat imminence and demonstrate that threat context evokes distinct parts of the fear system the human brain (Fanselow and Lester, 1988; Deakin and Graeff, 1991; Gray and McNaughton, 2000; McNaughton and Corr, 2004).

The so-called postencounter, which involves the detection but not interaction with a threat, is characterized in the rodent by passive defensives such as freezing, although flight is sometimes observed when escape is possible (Rau and Faneslow, 2007). Our results indicate that a postencounter threat preferentially engages the vmPFC, sgACC, pgACC, hippocampus, amygdala, and hypothalamus. Although other structures (e.g., ventrolateral PAG) are also engaged during a real "life-endangering" postencounter threat, the forebrain regions we describe are known to play a critical role in a postencounter threat by influencing visceral functions (Critchley et al., 2001), prediction, and prefiguring analgesic and strategic responses (Fanselow and Lester, 1988; Petrovic et al. 2002). These forebrain areas also have dense connections to the basolateral amygdala as well as the hypothalamus, hippocampus, and PAG, forming a critical component of a mPFC network that is known to exert control over these emotion systems (Price, 2005). The amygdala receives contextual input from the hippocampus (Phillips and LeDoux, 1992; LeDoux, 1996; Phelps and LeDoux, 2005) and is an integral component of the postencounter instigating behavioral reactions (e.g., ventrolateral PAG evoked freezing), vigilance (Whalen, 1998), as well as encoding information about the threat stimulus (Fanselow, 1994). The precise role of these forebrain structures is likely to encompass complex reactions to ecological dangers (Price, 2005), including the assignment and control of fear (Schiller et al., 2008).

The circa-strike is characterized by direct predator attack, which results in reactive defensive strategies. Self-report panic was significantly higher for the circa-strike than postencounter conditions as were SCLs, presumably reflecting increased autonomic sympathetic arousal (Critchley, 2002). Moreover, increased midbrain activity was observed, again supporting previous theory (Deakin and Graeff, 1991; Gorman et al., 2000; McNaughton and Corr, 2004). A previous study from our group showed that the midbrain is more active when a threat is spatially close during circa-strike attack (Mobbs et al., 2007). Nonetheless, the exact role of this region still remains unresolved. It is known that overactivity of the mid- brain PAG results in maladaptive responses such as panic, which manifest as uncoordinated behavior and loss of control (Graeff, 2004). Panic is defined as an overwhelming surge in behavior with robust flight (or fight) reactions (Bouton et al., 2001). Supporting the notion that panic is associated with uncoordinated behavior during inescapable threat (McNaughton, 1993), we found that midbrain activity increased with the amount of panicrelated locomotor errors for the $\mathrm{CS}_{\mathrm{HI}}-\mathrm{CS}_{\mathrm{LO}}$ threat (Fig. 4). Indeed, chemical stimulation of the rodent dorsolateral PAG elicits uncoordinated panic-like behaviors such as uncontrolled activity bursts (e.g., vigorous running and jumping) (Deakin and Graeff, 1991; Bandler et al., 2000; Vianna et al., 2001), whereas lesions to the same region eradicate such activity bursts to threat (Fanselow, 1991). We also observed increased activity in the middACC, a region with strong connectivity to the midbrain and implicated in panic (Asami et al., 2008). Indeed, damage to this region can cause panic attacks (Tamburin et al., 2008). Although future studies need to probe the role of these regions with different aversive stimuli, our observations suggest that the midbrain may reflect uncoordinated flight or panic-like behaviors.

The high-level processes instantiated in forebrain regions involving predictive coding, monitoring, and encoding of contingencies and uncertainty means that the time course of their response is likely to be slow, and contrast with an obligatory response profile of midbrain regions evoked during circa-strike (Fanselow and Lester, 1988; Mobbs et al., 2007; Ochsner et al., 2009). It follows that when circa-strike is initiated, it is optimal if these forebrain regions are inhibited (Fanselow and Lester, 1988; Butler et al., 2007; Martel et al., 2008). In support of this, we found decreased forebrain activity for the interaction between circa-strike contexts. Moreover, the amygdala and hippocampus, along with other regions of the forebrain, showed negative connectivity with the midbrain. However, the amygdala also showed negative connectivity with pgACC during the $\mathrm{CS}_{\mathrm{HI}}$ condition. These two findings are important in light of studies showing, on one hand, that the midbrain PAG results in inhibition of the amygdala during conditioned fear (Fanselow et al., 1995), whereas stimulation of the pgACC results in similar inhibition of the amygdala (Quirk et al., 2003). Our findings are in line with the notion that distinct divisions of the fear system are evoked during postencounter versus circa-strike contexts (Fanselow, 1994).

It has previously been suggested that shock probability essentially models distance on the predatory imminence continuum (Bolles and Fanselow, 1980; Fanselow and Lester, 1988). Compared with low probability, high probability of capture resulted in increased right vmPFC (i.e., pgACC) activity. We also found that the pgACC was primarily linked with decreased panic-related locomotor errors during the $\mathrm{CS}_{\mathrm{HI}}-\mathrm{CS}_{\mathrm{LO}}$ threat. Thus, when the subjects thought there was a low probability of shock, they had more controlled locomotor behaviors, yet the knowledge they were likely to be caught increased locomotor errors. The mPFC also regulates the amygdala and expression of fear (Phelps and LeDoux, 2005; Schiller et al., 2008) and extinction (Phelps et al., 2004) and augments hypothalamic stress hormones (Figueiredo et al., 2003). Stimulation of the mPFC homolog decreases activity in the rodent central nucleus of the amygdala (CeA) (Quirk et al., 2003). The CeA projects to the midbrain PAG and hypothalamus and acts as a control hub for fear responses (LeDoux, 1996). It is proposed that via GABAergic-intercalated cells, mPFC mediates the expression of fear by gating transmission from the basolateral amygdala to the CeA (Quirk et al., 2003; Bermpohl et al., 2006). Indeed, these regions have been shown to control stress reactions (Salomons et al., 2004; Amat et al., 2005; Salomons et al., 2007) 
and to be abnormal in patients with posttraumatic stress disorder and panic disorder (Zubieta et al., 1999; Asami et al., 2008; Uchida et al., 2008). Although one might argue that this activity reflects cognitive predictive process, which function independently from the emotional system, our findings support the notion that the vmPFC regulates the fear systems possibly via the amygdala (Reiman et al., 1989; Schiller et al., 2008). Similarly, it could be suggested that prefrontal cortex exerts inhibitory control on the fear system in the midbrain.

Although the current results only present contexts analogous to real defensive states, they are strongly consistent with brain antipredator defensive systems models developed in rodents (Deakin and Graeff, 1991; Gorman et al., 2000; McNaughton and Corr, 2004) and human psychiatric models of panic (Gorman et al., 2000). It is conceivable that distinct parts of the fear system are modulated by contextual factors expounded by the threat imminence continuum (Fanselow, 1995). For example, when a threat is spotted, slow, but accurate, higher parts of the fear system organize fear and preparatory responses. This higher threat system, however, is seemingly inhibited when the organism shifts to a circa-strike level of threat, which evokes responses associated with fast hard-wired defenses in the midbrain. Although our conclusions remain tentative and need further empirical verification, these evolutionary conserved systems are critical to the rapid switch in adaptive behavior, and we speculate that different symptoms associated with anxiety and panic are modulated by disruption to differential components of the fear circuitry.

\section{References}

Amat J, Baratta MV, Paul E, Bland ST, Watkins LR, Maier SF (2005) Medial prefrontal cortex determines how stressor controllability affects behavior and dorsal raphe nucleus. Nat Neurosci 8:365-371.

Amat J, Paul E, Zarza C, Watkins LR, Maier SF (2006) Previous experience with behavioral control over stress blocks the behavioral and dorsal raphe nucleus activating effects of later uncontrollable stress: role of the ventral medial prefrontal cortex. J Neurosci 26:13264-13272.

Asami T, Hayano F, Nakamura M, Yamasue H, Uehara K, Otsuka T, Roppongi T, Nihashi N, Inoue T, Hirayasu Y (2008) Anterior cingulate cortex volume reduction in patients with panic disorder. Psychiatry Clin Neurosci 62:322-330.

Ashburner J, Friston KJ (1999) Nonlinear spatial normalization using basis functions. Hum Brain Mapp 7:254-266.

Bandler R, Keay KA, Floyd N, Price J (2000) Central circuits mediating patterned autonomic activity during active vs passive emotional coping. Brain Res Bull 53:95-104.

Bermpohl F, Pascual-Leone A, Amedi A, Merabet LB, Fregni F, Gaab N, Alsop D, Schlaug G, Northoff G (2006) Attentional modulation of emotional stimulus processing: an fMRI study using emotional expectancy. Hum Brain Mapp 27:662-677.

Blanchard RJ, Blanchard DC (1990a) Anti-predator defense as models of animal fear and anxiety fear and defence. In: Fear and defence (Brain PF, Blanchard RJ, Mainardi D, eds), pp 89-108. Chur, Switzerland: Harwood Academic Publishers.

Blanchard RJ, Blanchard DC (1990b) An ethoexperimental analysis of defense, fear and anxiety. In: Anxiety (McNaughton N, Andrews G, eds), pp 24-33. Dunedin, New Zealand: Otago UP.

Bolles RCF, Fanselow MS (1980) A perceptual-defensive-recuperative model of fear and pain. Behav Brain Sci 3:291-301.

Bouton ME, Mineka S, Barlow DH (2001) A modern learning theory perspective on the etiology of panic disorder. Psychol Rev 108:4-32.

Burghardt NS, Bush DE, McEwen BS, LeDoux JE (2007) Acute SSRIs increase conditioned fear expression: blockade with a 5-HT2C receptor antagonist. Biol Psychiatry 62:1111-1118.

Butler T, Pan H, Tuescher O, Engelien A, Goldstein M, Epstein J, Weisholtz D, Root JC, Protopopescu X, Cunningham-Bussel AC, Chang L, Xie XH, Chen Q, Phelps EA, Ledoux JE, Stern E, Silbersweig DA (2007) Human fear-related locomotor neurocircuitry. Neuroscience 150:1-7.
Craske MG (1999) Anxiety disorders: psychological approaches to theory and treatment. Boulder, CO: Westview.

Critchley HD (2002) Electrodermal responses: what happens in the brain? Neuroscientist 8:132-142.

Critchley HD, Mathias CJ, Dolan RJ (2001) Neural activity in the human brain relating to uncertainty and arousal during anticipation. Neuron 29:537-545.

Davis M, Whalen PJ (2001) The amygdala: vigilance and emotion. Mol Psychiatry 6:13-34.

Dayan P, Huys Q (2009) Serotonin in affective control. Annu Rev Neurosci 32:95-126.

Deakin JFW, Graeff FG (1991) 5-HT and mechanisms of defence. J Psychopharmacol 5:305-315.

Deichmann R, Schwarzbauer C, Turner R (2004) Optimisation of the 3D MDEFT sequence for anatomical brain imaging: technical implications at 1.5 and 3 T. Neuroimage 21:757-767.

Fanselow MS (1991) The midbrain periaqueductal gray as a coordinator of action in response to fear and anxiety. In: The midbrain periaqueductal gray matter: functional, anatomical and immunohistochemical organization. (Depaulis A, Bandler R, eds), pp 151-173. New York: Plenum Publishing.

Fanselow MS (1994) Neural organization of the defensive behavior system responsible for fear. Psychon Bull Rev 1:429-438.

Fanselow MS, Lester LS (1988) A functional behavioristic approach to aversively motivated behavior: predatory imminence as a determinant of the topography of defensive behavior. In: Evolution and learning (Beecher MD, ed), pp 185-211. Hillsdale, NJ: Erlbaum.

Fanselow MS, DeCola JP, De Oca B, Landeira-Fernandez J (1995) Ventral and dorsolateral regions of the midbrain periaqueductal gray control different stages of defensive behavior: dorsolateral PAG lesions enhance the defensive freezing produced by massed and immediate shock. Aggress Behav 21:63-77.

Gorman JM, Kent JM, Sullivan GM, Coplan JD (2000) Neuroanatomical hypothesis of panic disorder, revised. Am J Psychiatry 157:493-505.

Graeff FG (2004) Serotonin, the periaqueductal gray and panic. Neurosci Biobehav Rev 28:239-259.

Gray JA, McNaughton N (2000) The neuropsychology of anxiety: an enquiry into the functions of the septohippocampal system, Ed 2. Oxford: Oxford UP.

Herman JP, Figueiredo H, Mueller NK, Ulrich-Lai Y, Ostrander MM, Choi DC, Cullinan WE (2003) Central mechanisms of stress integration: hierarchical circuitry controlling hypothalamo-pituitary-adrenocortical responsiveness. Front Neuroendocrinol 24:151-180.

Hutton C, Bork A, Josephs O, Deichmann R, Ashburner J, Turner R (2002) Image distortion correction in fMRI: a quantitative evaluation. Neuroimage 16:217-240.

Jhou TC, Fields HL, Baxter MG, Saper CB, Holland PC (2009) The rostromedial tegmental nucleus (RMTg), a GABAergic afferent to midbrain dopamine neurons, encodes aversive stimuli and inhibits locomotor responses. Neuron 61:786-800.

Josephs O, Houseman AM, Friston K, Turner R (1997) Physiological noise modelling for multi-slice EPI fMRI using SPM. In: Proceedings of the Fifth Annual Meeting of International Society for Magnetic Resonance in Medicine.

LeDoux JE (1996) The emotional brain. New York: Simon and Schuster.

Lowry CA, Hale MW, Evans AK, Heerkens J, Staub DR, Gasser PJ, Shekhar A (2008) Serotonergic systems, anxiety, and affective disorder: focus on the dorsomedial part of the dorsal raphe nucleus. Ann NY Acad Sci 1148:86-94.

Martel G, Nishi A, Shumyatsky GP (2008) Stathmin reveals dissociable roles of the basolateral amygdala in parental and social behaviors. Proc Natl Acad Sci U S A 105:14620-14625.

McNaughton N (1993) Stress and behavioural inhibition. In: Stress: an integrated approach (Stanford SC, Salmon P, eds), pp 191-206. San Diego: Academic.

McNaughton N, Corr PJ (2004) A two-dimensional neuropsychology of defense: fear/anxiety and defensive distance. Neurosci Biobehav Rev 28:285-305.

Mobbs D, Petrovic P, Marchant JL, Hassabis D, Weiskopf N, Seymour B, Dolan RJ, Frith CD (2007) When fear is near: threat imminence elicits prefrontal-periaqueductal grey shifts in humans. Science 317:1079-1083. Ochsner KN, Ray R, Robertson E, Cooper J, Gross JJ, and Gabrieli JDE 
(2009) Bottom-up and top-down processes in emotion generation. Psychol Sci, in press.

Petrovic P, Kalso E, Petersson KM, Ingvar M (2002) Placebo and opioid analgesia—imaging a shared neuronal network. Science 295:1737-1740.

Phelps EA, LeDoux JE (2005) Contributions of the amygdala to emotion processing: from animal models to human behavior. Neuron 48:175-187.

Phelps EA, Delgado MR, Nearing KI, LeDoux JE (2004) Extinction learning in humans: role of the amygdala and vmPFC. Neuron 43:897-905.

Phillips RG, LeDoux JE (1992) Differential contribution of amygdala and hippocampus to cued and contextual fear conditioning. Behav Neurosci 106:274-285.

Price JL (2005) Free will versus survival: brain systems that underlie intrinsic constraints on behavior. J Comp Neurol 493:132-139.

Quirk G, Beer JS (2006) Prefrontal involvement in emotion regulation: convergence of rat and human studies. Curr Opin Neurobiol 16:723-727.

Quirk GJ, Likhtik E, Pelletier JG, Paré D (2003) Stimulation of medial prefrontal cortex decreases the responsiveness of central amygdala output neurons. J Neurosci 23:8800-8807.

Rau V, Fanselow MS (2007) Neurobiological and neuroethological perspectives on fear and anxiety. In: Understanding trauma: integrating biological, clinical, and cultural perspectives (Kirmayer LJ, Lemesom R, Barad M, eds), pp 27-40. New York: Cambridge UP.

Reiman EM, Raichle ME, Robins E, Mintun MA, Fusselman MJ, Fox PT, Price JL, Hackman KA (1989) Neuroanatomical correlates of a lactateinduced anxiety attack. Arch Gen Psychiatry 46:493-500.

Robbins TW, Crockett MJ (2009) The role of serotonin in impulsivity and compulsivity: comparative studies in experimental animals and humans. In: The behavioral neurobiology of serotonin (Muller CP, Jacobs B, eds), in press.

Russell SJ, Norvig P (2003) Artificial intelligence: a modern approach. Upper Saddle River, NJ: Pearson Education.
Salomons TV, Johnstone T, Backonja MM, Davidson RJ (2004) Perceived controllability modulates the neural response to pain. J Neurosci 24:199-203.

Salomons TV, Johnstone T, Backonja MM, Shackman AJ, Davidson RJ (2007) Individual differences in the effects of perceived controllability on pain perception: critical role of the prefrontal cortex. J Cogn Neurosci 19:993-1003.

Schiller D, Levy I, Niv Y, LeDoux JE, Phelps EA (2008) From fear to safety and back-reversal of fear in the human brain. J Neurosci 28:11517-11525.

Tamburin S, Cacciatori C, Bonato C, Zanette G (2008) Cingulate gyrus tumor presenting as panic attacks. Am J Psychiatry 165:651-652.

Turner R, LeBihan D, Moonen CTW, Despres D, Frank J (1991) Echoplanar time course MRI of cat brain oxygenation changes. Magn Reson Med 27:159-166.

Uchida RR, Del-Ben CM, Busatto GF, Duran FL, Guimarães FS, Crippa JA, Araújo D, Santos AC, Graeff FG (2008) Regional gray matter abnormalities in panic disorder: a voxel-based morphometry study. Psychiatry Res 163:21-29.

Vianna MR, Izquierdo LA, Barros DM, de Souza MM, Rodrigues C, Sant'Anna MK, Medina JH, Izquierdo I (2001) Pharmacological differences between memory consolidation of habituation to an open field and inhibitory avoidance learning. Braz J Med Biol Res 34:233-240.

Weiskopf N, Hutton C, Josephs O, Deichmann R (2006) Optimal EPI parameters for reduction of susceptibility-induced BOLD sensitivity losses: a whole-brain analysis at $3 \mathrm{~T}$ and $1.5 \mathrm{~T}$. Neuroimage 33:493-504.

Whalen PJ (1998) Fear, vigilance, and ambiguity: initial neuroimaging studies of the human amygdala. Curr Dir Psychol Sci 7:177-188.

Zubieta JK, Chinitz JA, Lombardi U, Fig LM, Cameron OG, Liberzon I (1999) Medial frontal cortex involvement in PTSD symptoms: a SPECT study. J Psychiatr Res 33:259-264. 